\title{
IMPLEMENTASI CITA HUKUM DALAM MENCAPAI NILAI KEADILAN GUNA MEMBANGUN PEMIMPIN YANG BERKARAKTER DI KOTA PALEMBANG
}

\author{
Ning Herlina, Yanuar Syam Putra \\ Universitas PGRI Palembang \\ ning_141258@yahoo.com
}

\begin{abstract}
Abstrak
Hukum dalam perkembangannya, mendorong para ahli hukum untuk menghasilkan suatu definisi mengenai hukum. Dapat ditemukan bahwa definisi mengenai hukum yang dihasilkan oleh para ahli memiliki karakteristik yang berbeda satu dengan yang lain. Hal ini memiliki alasan bahwa dalam proses menghasilkan definisi tersebut para ahli memiliki sudut pandang yang berbeda. Jadi, Cita hukum ini harus memiliki bentuk, baik dalam tataran teoritis hingga pada tataran praktis. Pada tataran teoritis, cita hukum berawal pada tahap interpretasi yang berujung pada tataran Praktis, yaitu implementasi. Pada tahap interpretasi, cita hukum ini berawal dari konsep hukum itu sendiri. Adapun dalam penulisan penelitian ini, penulis menggunakan metode penelitian normatif-empiris melalui studi pustaka dari beberapa bahan buku dan media lainnya serta observasi lapangan di kota Palembang melalui wawancara.
\end{abstract}

\section{Kata Kunci : Hukum, Nilai Keadilan, Pemimpin.}

Abstract
The law in its development, encourages legal experts to get a resolution on law. Can be found with the resolution of the law produced by experts have different characteristics with the others. This has a reason in the process of producing these experts have different points of view. So, this legal ideal must have a form, from the legal level to the practical level. At the level of transition, the purpose of law starts at interpretation which ends at the practical level, namely implementation. At the interpretation stage, this legal idea starts with the concept of law itself. Regarding this research, the author uses the normative-empirical research method through library research from several book materials and other media as well as field observations in the city of Palembang through interviews.

Keywords: Law, Fair Value, Leader.

\section{A. Pendahuluan}

Hukum dalam perkembangannya, mendorong para ahli hukum untuk menghasilkan suatu definisi mengenai hukum. Dapat ditemukan bahwa definisi mengenai hukum yang dihasilkan oleh para ahli memiliki karakteristik yang berbeda satu dengan yang lain. Hal ini memiliki alasan bahwa dalam proses menghasilkan definisi tersebut para ahli memiliki sudut pandang yang berbeda. Maksudnya, hukum itu mengikuti perkembangan kehidupan manusia sehingga mempengaruhi pola pikir para ahli dalam membentuk elemen dasar yang mewujudkan definisi mengenai hukum. Pola pikir ini nantinya mengakibatkan unsur-unsur esensial yang membentuk hukum.

Sebagai contoh, disini akan dijabarkan mengenai pandangan yang berbeda tentang hukum dari 2 (dua) orang akhli hukum. Ia adalah John Austin. Dalam bukunya The Providence Of Jurisprudenc 
Determined, ia memiliki pemahaman mengenai hukum yakni law is commands, backed by treat of sanctions, from a sovereign to whom people have a habbit of obedience. Baginya, hukum itu tidak lain memiliki sifatnya yang imperatif dimana didukung oleh adanya sanksi sehingga mengakibatkan setiap orang terikat terhadap hukum. Pandangan Austin menghasilkan bahwa pemberlakuan hukum memiliki sifat yang sepihak. Hal ini memiliki artian bahwa hukum itu merupakan produk dari seseorang yang memiliki kekuasaan untuk memberlakukan secara menyeluruh dan mengikat.

Lebih lanjut, perbandingan mengenai pemahaman akan hukum ditujukan terhadap pandangan Jean-Jacques Rousseau. Menurutnya:

but what, after all, is a law? When I say that the object of laws is always general, $i$ mean the law consider subjects en messe and action.....on this view we at once see that it can no longer be asked whose business it is to make laws, since they are acts of the general will; nor whether the prince is above the law, since he is a member of the state; nor whether the law can be unjust, since no one is unjust to himself; nor how we can both free and subject to the laws, since they are but register of our wills ( Jean-Jacques Rousseau : The Social Contract, Book II : Chapter 6 ). ${ }^{1}$

Secara garis besar pemahamannya mengenai hukum ditujukan oleh adanya suatu pertemuan kehendak masyarakat. Hal ini memiliki makna bahwa kehendak yang dimiliki masing-masing individu dipertemukan dan dipersatukan untuk menghasilkan suatu peraturan yang menjaga ketertiban dalam kehidupan manusia.

Kedua konsep mengenai hukum yang dihasilkan oleh para akhli di atas memiliki perbedaan antara satu dengan yang lain. Perbedaan ini dilihat pada pandangan yang diutarakan oleh John Austin dan

\footnotetext{
${ }^{1}$ Internet, Diakses Tanggal 26 Mei 2011.
}

J.J.Rousseau mengenai unsur-unsur dasar dalam membentuk konsep mereka mengenai hukum. Hingga sekarang, dapat ditemukan berbagai perbedaan mengenai pembentuk konsep hukum di antara para akhli hukum. Akan tetapi, perbedaan itu sesungguhnya mengarah kepada cita hukum (rechtsidee) yang sama pada pola pikir para akhli hukum dalam membentuk konsep mengenai hukum. Cita hukum (rechtsidee) yang dimaksud, yakni : ketertiban, dapat diperhitungkan (predictable), kepastian hukum, dan keadilan.

Cita hukum ini harus memiliki bentuk, baik dalam tataran teoritis hingga pada tataran praktis. Pada tataran teoritis, cita hukum berawal pada tahap interpretasi yang berujung pada tataran Praktis, yaitu implementasi. Pada tahap interpretasi, cita hukum ini berawal dari konsep hukum itu sendiri. Hal ini berkaitan dengan unsur-unsur dalam pembentukan hukum yang selanjutnya akan diberlakukan.

Selanjutnya, tahap interpretasi ini berakhir pada tahap implementasi. Pada tahap ini hukum yang telah memiliki suatu bentuk akan diberlakukan kepada masyarakat. Akibatnya, setiap pihak yang berada dalam yurisdiksi hukum tersebut memiliki hak dan kewajiban berdasarkan hukum.

Kedua tahap ini yakni interpretasi dan implementasi, memiliki keterkaitan yang sangat erat. Maksudnya, cita hukum sudah harus tampak pada tahap interpretasi sehingga tidak menimbulkan kesulitan dalam tahap implementasi.

Permasalahan yang dapat terjadi bilamana cita hukum itu tidak dapat dicapai baik dalam tataran tersebut di atas. Sebagai contoh, ada kalanya suatu Undang-Undang (UU) tidak sepenuhnya meliputi keseluruhan dari cita hukum yang ada. Selintas mengenai UU Pornografi, memang dirasa dapat mewujudkan suatu ketertiban bagi masyarakat dalam meningkatkan moral yang kemudian tujuan itu mendapatkan suatu bentuk kepastian dalam penegakannya. Akan tetapi, bila dilihat lagi, apakah dengan pemberlakuan UU tersebut dapat mencipta- 
kan keadilan bagi masyarakat Indonesia yang beraneka ragam adat? Keadilan merupakan permasalahan utama dalam proses pembentukan, pemberlakuan dan penegakan hukum. Keadilan merupakan salah satu bagian dari cita hukum yang paling sulit untuk dicapai. Hal ini dikarenakan bahwa konsep keadilan sangat bersifat abstrak dan relatif. Maksudnya, setiap orang memiliki penilaian yang bersifat otonom dalam mengaplikasikan keadilan. Oleh karena itu kami sebagai penulis mengkaji hal ini dari pokok permasalahan yaitu sebagai berikut: Bagaimana penegakan hukum dalam mencapai nilai keadilan guna membangun Pemimpin yang berkarakter di kota Palembang? Dengan tujuan untuk menganalisa implementasi nilai keadilan guna membangun pemimpin yang berkarakter di kota Palembang, dan manfaat dari penelitian ini agar secara umum bahwa setiap masyarakat diharapkan dapat mengetahui cara memilih seorang pemimpin yang adil serta berkarakter yang baik guna meningkatkan dari kualitas seorang pemimpin yang ada di kota Palembang ini.

Kemudian setelah mengetahui berbagai macam nilai, makna, dan jenis nilai di dalam hukum, maka kami sebagai penulis akan mengkaji masalah nilai Keadilan dalam Pancasila yang dikaitkan dengan penelitian yang berjudulkan "Implementasi Cita Hukum dalam Mencapai Nilai Keadilan guna Membangun Pemimpin yang Berkarakter di Kota Palembang".

\section{B. Permasalahan}

Peneliti mengkaji hal ini dari satu permasalahan saja yaitu sebagai berikut:

Bagaimana penegakan hukum dalam mencapai nilai keadilan guna membangun $\mathrm{Pe}$ mimpin yang berkarakter di kota Palembang?

\section{Pembahasan}

Implementasi Cita Hukum dalam Mencapai Nilai Keadilan guna Membangun Pemimpin yang Berkarakter di Kota Palembang
Etika kepemimpinan bagi Pemimpin Nasional berhimpitan dengan moral kepemimpinan yang berdasarkan Pancasila. Etika kepemimpinan merupakan tindak lanjut dari moral kepemimpinan. Karena etika kepemimpinan bagi Pemimpin Nasional merupakan aktualisasi nilai-nilai instrumental Pancasila yang terpatri dalam UUD NRI 1945. Nilai intrumental Pancasila yang menjadi muatan UUD NRI 1945 sebagai landasan konstitusional berbangsa dan bernegara adalah instrumen keorganisasian, kelembagaan, kekuasaan dan kebijaksanaan pemerintah. $^{2}$

Dalam Kamus Besar Bahasa Indonesia, integritas adalah mutu, sifat, atau keadaan yang menunjukkan kesatuan yang utuh sehingga memiliki potensi dan kemampuan yang memancarkan kewibawaan dan kejujuran. Menurut Mario Teguh (motivator), mengatakan bahwa integritas adalah kesetiaan kepada yang benar. Hal ini sejalan dengan pengertian integritas menurut Wikipedia yang berarti suatu konsep yang menunjuk konsistensi antara tindakan dengan nilai dan prinsip. Nilai dan prinsip ini tentunya tidak lepas dari kebenaran. Oleh karena itu orang yang memiliki integritas pasti akan menjadi orang yang jujur dan menyukai keadilan.

Oleh karena itu karakter bangsa dibentuk oleh berbagai campuran dari sifatsifat yang ada, seperti: ketaqwaan, ketulusan, kejujuran, kebanggaan, keterbukaan, kerja keras, dan tanggung jawab serta semangat untuk berprestasi. Karakter bangsa akan muncul sebagai keterpaduan dan keseimbangan dari berbagai karakteristik moral di atas. Oleh karena itu, karakter bangsa Indonesia harus dikembangkan berdasarkan nilai-nilai tradisi yang dimiliki dipadukan dengan konteks bangsa yang ada seperti, lembaga-lembaga, kebiasaan-kebiasaan, dan kebudayaan bangsa serta agama

${ }^{2}$ Sudarwan Danim, 2010, Kepemimpinan Pendidikan (Kepemimpinan Jenius (IQ+EQ), Etika, Perilaku Motivational dan Mitos), Bandung: Alfabeta Sidharta, Hlm. 45. 
yang dianut oleh warga bangsa Indonesia, sebagaimana yang tercantum dalam Pancasila dan UUD Negara RI Tahun 1945. Karena karakter adalah sistem daya juang yang menggunakan nilai-nilai moral yang terpatri pada diri kita yang melandasi pemikiran, sikap dan perilaku.

Namun dalam jiwa kepemimpinan juga memerlukan suatu komitmen, dimana komitmen adalah kemampuan dan kemauan untuk menyelaraskan perilaku pribadi dengan kebutuhan, prioritas dan tujuan organisasi. Hal ini mencakup cara-cara mengembangkan tujuan atau memenuhi kebutuhan organisasi yang intinya mendahulukan misi organisasi dari pada kepentingan pribadi. ${ }^{3}$ Menurut Meyer dan Allen $1991^{4}$, komitmen dapat juga berarti penerimaan yang kuat individu terhadap tujuan dan nilai-nilai organisasi, dan individu berupaya serta berkarya dan memiliki hasrat yang kuat untuk tetap bertahan di organisasi tersebut.

Menurut Van Dyne dan Graham $2005^{5}$, faktor-faktor yang mempengaruhi komitmen organisasi adalah: personal, situasional dan posisi. Personal mempunyai ciri-ciri kepribadian tertentu seperti, kepribadian ektrovert, berpandangan positif (optimis), cenderung lebih komit. Lebih lanjut Dyen dan Graham $2005^{6}$ menjelaskan karakteristik dari personal yang ada yaitu: usia, masa kerja, pendidikan, jenis kelamin, status perkawinan, dan keterlibatan kerja. Situasional yang mempunyai ciri-ciri dengan adanya: nilai (value) tempat kerja, keadilan organisasi, karakteristik pekerjaan, dan dukungan organisasi. Sedangkan posisional dipengaruhi oleh masa kerja dan tingkat pekerjaan.

${ }^{3}$ Mulyono, 2009, Educational Leadership (Mewujudkan Efektivitas Kepemimpinan Pendidikan), Malang: UIN Malang Press, Hlm. 100.

4 Ibid., Hlm. 83.

5 Kazan Gunawan Muladi, 2007, Transformasi Geopolitik, Pusat Pengkaji Strategi Nasional, Jakarta, Hlm. 23.

${ }^{6}$ Ibid., Hlm. 55.
Menurut Quest $1995^{7}$ indikator-indikator perilaku komitmen yang dapat dilihat pada karyawan adalah :

a. Melakukan upaya penyesuaian, dengan cara agar cocok di organisasinya dan me lakukan hal-hal yang diharapkan, serta menghormati norma-norma organisasi, menuruti peratu-ran dan ketentuan yang berlaku.

b. Meneladani kesetiaan, dengan cara membantu orang lain, menghormati dan menerima hal-hal yang dianggap penting oleh atasan, bangga menjadi bagian dari organi-sasi, serta peduli akan citra organisasi.

c. Mendukung secara aktif, dengan cara bertindak mendukung misi memenuhi kebutuhan/misi organisasi dan menyesuaikan diri dengan misi organisasi.

d. Melakukan pengorbanan pribadi, dengan cara menempatkan kepentingan organisasi diatas kepentingan pribadi, pengorbanan dalam hal pilihan pribadi, serta mendukung keputusan yang menguntungkan organisasi walaupun keputusan tersebut tidak disenangi.

Setelah seorang pemimpin memiliki komitmen maka suatu kompetensi pun sangat diperlukan guna menunjang kepemimpinannya yang akan datang. Hal itu dikarenakan Kompetensi mengandung pengertian pemilikan pengetahuan, keterampilan, dan kemampuan yang dituntut oleh jabatan tertentu. ${ }^{8}$ Kompetensi dimaknai pula sebagai pengetahuan, keterampilan, dan nilai-nilai dasar yang direfleksikan dalam kebiasaan berfikir, dan bertindak. Kompetensi dapat pula dimaksudkan sebagai kemampuan melaksanakan tugas yang diperoleh melalui pendidikan dan/atau latihan.

Dalam Kamus Besar Bahasa Indonesia, kompetensi adalah kewenangan (kekuasaan) untuk menentukan atau memutuskan sesuatu hal. Menurut Finch dan

\footnotetext{
${ }^{7}$ Mulyono, 2009, Op.Cit., Hlm. 20.

${ }^{8}$ Budi Hardiman Fransisco, 1990, Kritik

dan Ideologi, Pertautan Pengetahuan dan Kepentingan, Kanisius: Yogyakarta, Hlm. 40.
} 
Crunkilton ${ }^{9}$ bahwa yang dimaksud dengan kompetensi adalah penguasaan terhadap suatu tugas, ketrampilan, sikap, dan apresiasi yang diperlukan untuk menunjang keberhasilan. Hal itu menunjukkan bahwa kompetensi mencakup tugas, ketrampilan sikap dan apresiasi yang harus dimiliki peserta didik untuk dapat melaksanakan tugas-tugas pembelajaran sesuai dengan jenis pekerjaan tertentu.

Sedangkan menurut Broke dan Stone $^{10}$ kompetensi merupakan gambaran hakikat kualitatif dari perilaku guru yang tampak sangat berarti. Selanjutnya kompetensi menurut UU No. 13/2003 tentang Ketenagakerjaan: pasal 1 (10), "Kompetensi adalah kemampuan kerja setiap individu yang mencakup aspek pengetahuan, keterampilan dan sikap kerja yang sesuai dengan standar yang ditetapkan".

Jadi dapat dikatakan bahwa kompetensi adalah sebuah pernyataan terhadap apa yang seseorang harus lakukan ditempat kerja untuk menunjukan pengetahuannya, keterampilannya dan sikap sesuai dengan standar yang dipersyaratkan, disamping itu juga harus mencakup lima dimensi dari kompetensi:

a. Task skills - mampu melakukan tugas per tugas.

b. Task management skills-mampu mengelola beberapa tugas yang berbeda dalam pekerjaan

c. Contingency management skills : tanggap terhadap adanya kelainan dan kerusakan pada rutinitas kerja.

d. Environment skills/job role : mampu menghadapi tanggung jawab dan harapan dari lingkungan kerja/ beradaptasi dengan lingkungan.

e. Transfer skills: Mampu mentransfer kompetensi yang dimiliki dalam setiap situasi yang berbeda (situasi yang baru/ tempat)

9 Adi Sujatno Muladi, 2009, Raktat Etis Kemimpinan Nasional dan IKNI, Jakarta, Hlm.105.

${ }^{10}$ Andrias Harefa, 2000, Menjadi Manusia Pembelajar, Jakarta: Kompas Media Nusantara, HIm. 14.
Memperhatikan batasan pengertian tentang kompetensi di atas, maka kompetensi yang hams dimilki oleh Pemimpin Nasional yang diakui oleh masyarakat dan bermanfaat bagi kehidupan bermasyarakat, berbangsa dan bernegara. Kompetensi yang diakui oleh masyarakatnya merupakan sesuatu yang sangat diharapkan sesuai dengan situasi dan permasalahan yang dihadapi oleh masyarakat pada saat itu. Apa yang dilakukan oleh Bung Kamo pada jamannya untuk menunjukkan jadi diri bangsa Indonesia sebagai bangsa yang baru merdeka dengan kemampuannya sebagai orator ulung dapat memberikan kepercayaan kepada masyarakat akan keyakinan arah yang dituju sebagai suatu bangsa. Hal yang sama juga yang ditampilkan oleh Suharto sebagai Presiden RI ke 2, berbeda waktu dan situasi dengan Bung Karno, tetapi juga diakui oleh masyarakat akan arah yang dituju dalam mewujudkan tujuan nasional, demikian pula halnya dengan pemimpin nasional baik di pusat maupun di daerah.

Jadi diharapkan juga untuk memimpin bernilai keadilan guna memliki karakter seorang kepemimpinan yang bijak haruslah memenuhi hal Etika, Integritas, Komitmen, dan Kompetensi sebagai seorang pemimpin agar dapat mencapai nilai-nilai keadilan di masyarakat.

\section{Kesimpulan}

Berdasarkan pembahasan di atas maka peneliti dapat menyimpulkan bahwa untuk menjadi seorang pemimpin yang berkarater dan bernilai-nilai keadilan haruslah memperhatikan beberapa kriteria seperti halnya: Etika, Etika, Integritas, Komitmen, dan Kompetensi guna mendukung karakter jiwa kepemimpinan di kota Palembang. 


\section{DAFTAR PUSTAKA}

Buku:

Adi Sujatno Muladi. 2009. Raktat Etis Kemimpinan Nasional dan IKNI. Jakarta.

Budi Hardiman Fransisco. 1990. Kritik dan Ideologi, Pertautan Pengetahuan dan Kepentingan. Kanisius: Yogyakarta.

Hamid Patilima. Cetakan Ke-2, Desember 2007. Metode Penelitian Kualitatif. Penerbit: Alfabeta. Bandung.

Andrias Harefa. 2000. Menjadi Manusia Pembelajar. Jakarta: Kompas Media Nusantara.

Jujun S. Suriasumantri. Cetakan Ke-6. November 1990. Filsafat Ilmu Sebuah Pengantar Populer. Penerbit: PT Gelora Aksara Pratama. Jakarta.

Kazan Gunawan Muladi. 2007. Transformasi Geopolitik, Pusat Pengkaji Strategi Nasional. Jakarta.

Mulyono. 2009. Educational Leadership (Mewujudkan Efektivitas Kepemimpinan Pendidikan). Malang: UIN Malang Press.

Soerjono Soekanto. Cetakan Ke-3 Tahun 1986. Pengantar Penelitian Hukum, Penerbit: Universitas Indonesia. Jakarta.

Sudarwan Danim. 2010. Kepemimpinan Pendidikan (Kepemimpinan Jenius (IQ+EQ), Etika, Perilaku Motivational dan Mitos). Bandung: Alfabeta Sidharta.

Zainuddin Ali. Cetakan Ke-2. Agustus 2010. Metode Penelitian Hukum. Penerbit: Sinar Grafika. Jakarta.

\section{Internet:}

http://www.scribd.com/doc/11658267/Ketika-Keadilan-Merupakan-Cita-Hukum-Yang-

Ditinggalkan Diakses Tanggal 26 Mei 2011. 